\title{
The Effect of Dynamic Assessment on Iranian EFL Learners' Reading Comprehension
}

\author{
Mohammad Reza Amirian \\ Department of English Language, Faculty of Literature and Humanities, Hakim Sabzevari University, Sabzevar, Iran \\ E-mail: sm.amirian@hsu.ac.ir \\ Mohammad Davoudi \\ Department of English Language, Faculty of Literature and Humanities, Hakim Sabzevari University, Sabzevar, Iran \\ E-mail: davoudi2100@yahoo.com \\ Mohsen Ramazanian \\ Department of English Language, Faculty of Literature and Humanities, Hakim Sabzevari University, Sabzevar, Iran \\ E-mail: Ramazanian_mohsen@yahoo.com
}

Doi:10.7575/aiac.alls.v.5n.3p.191

URL: http://dx.doi.org/10.7575/aiac.alls.v.5n.3p.191
Received: $18 / 04 / 2014$

Accepted: 23/05/2014

\begin{abstract}
Dynamic Assessment (DA), is grounded in Vygotsky's idea on Sociocultural Theory (SCT) of mind, his concept of Zone of Proximal Development (ZPD) and its related metaphor; scaffolding. This study examined the effects of dynamic assessment on improving reading comprehension of Iranian intermediate students who were learning English as a foreign language. The participants, a group of Iranian male intermediate EFL learners ranging in age from 17 to 20 , were randomly assigned to two groups of 14. In this study, the experimental and control groups' performances on pretests and post-tests were compared through paired-samples and independent-samples t-tests. The treatment period lasted for 2 months (16 sessions). The results showed that the experimental group, which was instructed through DA, outperformed the control group which was instructed in a non-dynamic way.
\end{abstract}

Keywords: Dynamic Assessment, Zone of Proximal Development (ZPD), Sociocultural Theory, Reading comprehension

\section{Introduction}

Teaching methods have been incorporated in different areas of language learning trend. Mostly, they focus on presenting, delivering, or constructing knowledge. Measuring learners' knowledge has been part of methods. However, testing has been regarded as a peripheral issue. Nowadays, testing is assumed as a separate part from methodology in applied linguistics field. Different words and expressions have been used for technical equivalent of measuring learners' knowledge during different periods (Bachman \&Palmer, 1996). Including test, measurement, evaluation, and assessment are mentioned (Bachman \& Palmer, 1996). These names are different as their definitions vary. Conventionally, assessment has been defined as an information-gathering activity to gain insight into learners' current level of knowledge or ability (Baily, 1996; McNamara, 2004).

Most traditional assessment tends to measure learners' current development or what the learners' have already achieved, and thus it is also called "static assessment" by some researchers (Feuerstein et al., 1979). In addition, the focus was on the product of teaching and learning. New trends in research and psychology dedicate a great part to process of learning. Learners' feeling, emotion, and activity during learning process are at the center of focus. Moreover, researchers believe that proximal development will be effective if is activated (Poehner, 2005). DA is a method of teaching and testing that can solve this problem, which was drawn from SCT of Vygotsky and his idea on cognitive development opens new insights into assessment in the language classroom by revealing hidden aspects of individuals' abilities in answering each test item. While the results of traditional non-dynamic assessment (NDA) can only show the already existent abilities of the student, the analysis of ZPD makes it possible to evaluate the ability of the student to learn from the interaction with a teacher or a more competent peer and predict their possible future development (Ajideh et al, 2012).

Vygotsky (1978) defines ZPD as the difference between what a child can do independently and what the same child can achieve with mediation and DA looks at cognitive development within the context of social interactions with others who are more capable. Feuerstein, Rand and Rynders (1988) suggest that assessing practitioners are often "all too eager to accept an individual's present level of functioning as an absolute indicator of her potential future abilities, not taking into account that these abilities can be changed" (p. 83). 
In this study, the effect of DA is examined on Iranian EFL learners' reading comprehension through a process of testtreatment-test in quantitative part. This part aims at answering the question: Is there any statistically significant difference between learners' performance on reading comprehension when they are taught based on DA and its nondynamic counterpart?

\section{Method}

\subsection{Participants}

The sample consisted of 28 Iranian intermediate EFL learners who took English classes in a private institute. They were drawn from students who were English learner in a private Institute, based on a TOEFL test and assigned to two groups randomly. Each class had 14 male learners. For all of the participants, the Persian language was their first language and the English language was their foreign language. In order to ensure homogeneity of the samples in terms of their level of proficiency, the researcher just included those students whose scores obtained from TOEFL test fell one standard deviation below or above the mean and ignored the rest.

\subsection{Instrument}

\subsubsection{A TOEFL Test}

A TOEFL test was used to determine proficiency level of learners. The purpose of this test was to ascertain that the participants were homogeneous in terms of language level.

\subsubsection{Reading test}

For the pretest and posttest of the study, the same test was used. The test (Objective PET), which had been developed with the purpose of measuring intermediate learner's knowledge in reading comprehension by Cambridge University was used to measure the participants' knowledge before and after providing instruction. The test was in multiple-choice form and consisted of 35 items.

\subsection{Materials}

The Intermediate Select Reading book written by Linda lee and Erik Gundersen (2001) was employed in this study.

The book consists of 14 chapters. Each chapter starts with a picture and the sketch of chapter. After that, before going to the reading text, some general questions are presented. Then, reading text comes. Next, a short biography of the writer is followed. After that, some questions are used to check learner's comprehension. During exercises, some grammatical points are explained. Activities vary from recognizing questions (true and false) to production types (writing a summary). As it moves forward the difficulty of texts increases.

\subsection{Procedures}

Dynamic assessment instruction was applied in this group. At first reading comprehension was explained by the teacher. The aim of reading comprehension and different strategies, points, explanation, techniques and instruction were presented. The teacher used some models to complete the process before going to main work. If there were some questions and misunderstandings, they were responded, too. DA assessment instruction was explained as well. The participants were told about their duty during classes. This stage was the whole class demonstration (this method is used in interventionist DA).

Different strategies and techniques for reading comprehension were taught to the control group as well as the experimental group by the same teacher. But, this group was trained in a non-dynamic way.

\subsection{Data Collection}

The pre-test and post-test were the same, Objective PET test by Cambridge University Press was used in the study. The test was in multiple-choice format. It was scored by the teacher.

Through the use of SPSS, the descriptive statistics (mean scores and standard deviations, t-tests, etc.) for both the control and experimental groups were computed. After eliciting the required data and confirming normality of data, to compare the mean scores of post-tests for both groups, an independent-samples-t-test was implemented. In other words, an independent-samples-t-test was applied to see if the mean differences are statistically significant.

\section{Results and Discussion}

\subsection{Results of the TOEFL Test}

In order to make the sample homogeneous, a placement test was administered to 50 students. Then, 28 of them were selected as the participants of this study. They were selected based on the mean score of the test. Those students whose scores fell one SD above or below the mean were ignored. The descriptive data of the TOEFL test are presented in Table 3.1.

Table 3.1 Descriptive Statistics for TOEFL Test

$\mathrm{N} \quad$ Minimum Maximum $\quad$ Mean Std. Deviation




\subsection{Results of Pretests for Both Groups}

After confirming normality of data, to compare the mean scores of the control and experimental groups before treatment, a pretest was given. To capture the initial differences between the means of the two groups on pretest, an independent-samples-t-test was conducted. Table 3.2 displays the results of the independent-samples-t-test of the pretest.

Table 3.2 Independent Samples T-Test for Pretest
Mean
Std. Deviation
Std. Error Mean
df $\quad$ Sig. (2-tailed)

\begin{tabular}{lrrrrrr} 
Exp. & 22.35 & 3.79 & 1.01 & .16 & 26 & .871 \\
Con. & 22.14 & 3.08 & .82 & & & \\
\hline
\end{tabular}

Based on Table 3.2, there was no significant difference in scores for the control group $(\mathrm{M}=22.14, \mathrm{SD}=3.08)$ and the experimental group ( $\mathrm{M}=22.35, \mathrm{SD}=3.79 ; \mathrm{t}(26)=.16, \mathrm{p}=.871$, two-tailed $)$.

\subsection{Results of Pretest and Post-test in the Experimental Group}

To see the change in experimental performance, a test was given to the participants at the end of treatment. A pairedsamples-t-test was run between the pretest and post-test scores of the experimental group. Results are presented in Table 3.3.

Table 3.3 Paired-Samples T-Test for Experimental Group

Mean Std. Deviation Std. Error $\quad$ Mean $\quad$ df Sig. (2-tailed)

\begin{tabular}{lllllll}
\hline & \multicolumn{5}{c}{ Mean } \\
Pretest & 22.35 & 3.79 & 1.01 & 3.79 & 13 & .002 \\
& & & & & & \\
Post-test & 26.85 & 2.50 & .67 & & & \\
\hline
\end{tabular}

Results of paired-samples-t-test of the pretest and post-test in the experimental group showed that there was a significant difference between scores from pretest $(\mathrm{M}=22.35, \mathrm{SD}=3.79)$ to post-test $(\mathrm{M}=26.85, \mathrm{SD}=2.50), \mathrm{t}(13)=3.79$, $\mathrm{P}=.002<.05$ (two-tailed). The eta-squared statistic $(0.54)$ indicated a large effect size based on Cohen (1988).

\subsection{Results of Post-tests in Both Experimental and Control Groups}

To compare the post-tests of both groups an independent-samples-t-test was conducted. The following table (Table 3.4) manifests the results of this test.

Table 3.4 Independent Samples T-Test for Post-Test

\begin{tabular}{|c|c|c|c|c|c|c|}
\hline & Mean & Std. Deviation & $\begin{array}{l}\text { Std. Error } \\
\text { Mean }\end{array}$ & $\mathrm{t}$ & $\mathrm{df}$ & Sig. (2-tailed) \\
\hline Exp. & 26.85 & 2.50 & .67 & & 3.36 & $26 \quad .002$ \\
\hline Con. & 23.502 .76 & .73 & & & & \\
\hline
\end{tabular}

An independent-samples-t-test was run to compare the control and experimental post-test scores. There was a statistically significant difference in scores for control group $(\mathrm{M}=23.50 \mathrm{SD}=2.76)$ and experimental group $(\mathrm{M}=26.85$, $\mathrm{SD}=2.50) ; \mathrm{t}(26)=3.36, \mathrm{P}=0.02<0.05$ two-tailed). The eta squared statistic $(0.31)$ indicated a medium effect size based on Cohen (1988).

Due to the previous tables and results, it could be claimed that the experimental group outperformed the control group since there was a significant statistical difference between post-test scores of both groups and also a significant statistical difference between the experimental group pretest and post-test scores.

The change in the mean scores of the experimental group in pretest and post-test from $\mathrm{M}=22.35$ to $\mathrm{M}=26.85$ indicates that the participants obtained a significant improvement in their reading comprehension after the treatment. There was a great gap between experimental group performance and control group performance. To determine if this development was produced by the treatment or not, an independent-samples-t-test and a paired-samples-t-test were carried out. In 
both cases, the level of significance was less than the probability value $(0.05)$. Therefore, it might be claimed that these statistically significant differences were due to the treatment and the null hypothesis of no differences can be safely rejected.

\section{Conclusion}

The present study examined the influences of DA on reading comprehension of Iranian students who were learning English as a foreign language. Two different groups of participants were taught based on DA and non-DA instruction to see which group performs better on post-test. The result showed that experimental group, which was taught based on DA instruction outperformed control group, which was taught based on non-DA instruction.

The findings of the study provide support for Vygotsky's claim regarding evolutionary and revolutionary nature of development. With regard to DA methodology, this study makes a major contribution to the delivery of mediation, in particular with regard to reading comprehension.

Voice recording the learners was problematic as well. It was stressful for them. That was clear that it affected their performances to some extent, especially initial sessions. This factor acted like a mediator variable during the study.

Controlling class in situation that students work freely and is full of noise is difficult which was obvious in this study.

\section{References}

Ajideh, P., Farrokhi, f., \& Nourdad, N. (2012). Dynamic assessment of EFL reading: Revealing different aspects of different proficiency levels. World Journal of Education 4(2), 102-111.

Bachman, F. L., \& Palmer, A. S. (1996). Language testing in practice. Oxford: Oxford University Press.

Bailey, K. (1996). Working for washback: A review of the washback concept in language testing. Language Testing, 13 (3), 257-279.

Feuerstein, R., Rand, Y. \& Hoffman, M. B. (1979). The dynamic assessment of retarded performers: The learning potential assessment device: Theory, instruments, and techniques. Baltimore: University Park Press.

McNamara, T. (2004). Language testing. In A. Davies \& C. Elder (Eds.), The handbook of Applied Linguistics (pp. 763-783). Malden, MA: Blackwell.

Poehner, M. E. (2005). Dynamic assessment of oral proficiency among advanced L2 learners of French, Unpublished Ph.D. dissertation. The Pennsylvania State University, University Park, PA.

Vygotsky, L. (1962). Thought and language. Cambridge, MA: MIT Press. http://dx.doi.org/10.1037/11193-000. 